\title{
Mitral valve: anatomy, function of the mitral valve apparatus and the epidemiology of mitral stenosis and regurgitation
}

\section{(D)Dean Strinić* (DT)a Friščić}

University Hospital "Sveti Duh", Zagreb, Croatia
RECEIVED:

April 28, 2018

ACCEPTED:

May 10, 2018
KEYWORDS: mitral valve apparatus, epidemiology, mitral stenosis, mitral regurgitation CITATION: Cardiol Croat. 2018;13(5-6):177. | https://doi.org/10.15836/ccar2018.177

*ADDRESS FOR CORRESPONDENCE: Dean Strinić, Klinička bolnica „Sveti Duh“, Sv. Duh 64, HR-10000 Zagreb, Croatia. / Phone: +385-91-534-5973 / E-mail: destrinic@gmail.com

ORCID: Dean Strinić, https://orcid.org/0000-0001-6345-2037 • Tea Friščić, https://orcid.org/0000-0003-3189-8661
IIIIIIIIIIIIIIIIIIIIIIIIIIIIIIIIIIIIIIIIIIIIIIIIIIIIIIIIIIIIIIIIIIIIIIIIIIIIIIIIIIIIIIIIIIIIIIIIIIIIIIIIIIIIIIIIIIIIII

Mitral valve (MV) function depends on the coordinated action of the anatomic components of the mitral apparatus which is formed by two leaflets, annulus, chordae tendineae, and the papillary muscles (PM). The annulus is a saddle-shaped structure with a fixed portion (the anterior leaflet (AML) which is semilunar in shape) shared with the aortic annulus, and a dynamic portion (the quadrangular-shaped posterior leaflet (PML) composed of three scallops) that represents most of the circumference of the annulus $^{1}$. The surface area of the leaflets is twice the area of the mitral orifice which results in a large area of coaptation when the valve closes. The annulus to leaflet transition zone contains atrial myocytes with nerve fibres which extend from the mitral annulus, maintaining electrophysiological continuity with the rest of the heart ${ }^{2}$. The commissures are a distinct area where the AML and PML come together. Along the free edge of the leaflets the chordae tendineae are inserted through multiple locations with the other end attached to the tips of the anterolateral and posteromedial PM${ }^{3}$. The PM and the adjacent wall attach the mitral apparatus to the left ventricle. Diseases of the MV are valvular stenosis (MS), regurgitation (MR) and prolapse. MS is usually caused by rheumatic heart diseases (RHD). The prevalence of RHD in the USA and Japan stands at 0.6-0.7/1,000, which contrasts with that in the developing countries of Africa and Asia where rates are 30/1,000. Congenital MS is rare and is typically diagnosed in infancy or early childhood. MR is the result of structural or functional abnormalities of the MV apparatus. Functional abnormalities causing MR include myxomatous MV diseases, leaflet prolapse, RHD, infective endocarditis, coronary artery diseases and cardiomyopathy. Degenerative disease is the most common form MR in Europe (with an estimated prevalence of 2-3\%) and other developed countries. Ischemic MR affects 19\% of patients after myocardial infarction.

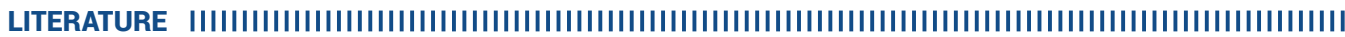

1. Levine RA, Hagége AA, Judge DP, Padala M, Dal-Bianco JP, Aikawa E, et al; Leducq Mitral Transatlantic Network. Mitral valve disease-morphology and mechanisms. Nat Rev Cardiol. 2015 Dec;12(12):689-710. https://doi.org/10.1038/nrcardio.2015.161

2. Chandran KB, Kim H. Computational mitral valve evaluation and potential clinical applications. Ann Biomed Eng. 2015 Jun;43(6):1348-62. https://doi.org/10.1007/s10439-014-1094-5

3. Ayoub S, Ferrari G, Gorman RC, Gorman JH, Schoen FJ, Sacks MS. Heart Valve Biomechanics and Underlying Mechanobiology. Compr Physiol. 2016 Sep 15;6(4):1743-1780. https://doi.org/10.1002/cphy.c150048 